\title{
ERRATUM
}

Takeshi Yamaguchi

\section{Influence of urbanization on ant distribution in parks of \\ Tokyo and Chiba City, Japan \\ I. Analysis of ant species richness}

Published online: 12 February 2005

(C) The Ecological Society of Japan 2005

\section{Ecological Research (2004) 19:209-216}

The legends for Fig. 1 and Fig. 2 of this article were transposed by mistake. The correct figure legends are as follows:

Fig. 1. The locations of investigated parks $(\bigcirc)$ in the 23 wards of Tokyo and those in Chiba City, Japan.
Fig. 2. Regression of the $\log _{10}$ number of ant species in a park $v s$ the $\log _{10}$ area of the park in Tokyo $(\bullet)$ $\left(y=0.3188 \mathrm{x}-0.1968 ; R^{2}=0.6191\right)$ and in Chiba $(\bigcirc)$ $\left(y=0.1344 \mathrm{x}+0.5843 ; R^{2}=0.2197\right)$

The online version of the original article can be found at http:// dx.doi.org/10.1111/j.1440-1703.2003.00625.x

T. Yamaguchi

Natural History Museum and Institute,

Chiba, 955-2 Aoba-cho, Chuo-ku,

Chiba 260-8682, Japan

E-mail: yamaguchi@chiba-muse.or.jp 